\title{
Family Size and Parents' Socio-economic Variables as Predictors of Investment in Children Education in South-West Nigeria
}

\author{
Nelson Ejiro Akpotu*1, Dauglason G. Omotor**2 and Dickson Onoyase* \\ *Department of Educational Administration and Policy Studies, **Department of Economics, \\ Delta State University, Abraka, Nigeria \\ E-mail: $1<$ neakpotu@yahoo.com>2<yomotor@yahoo.com>
}

KEYWORDS Family; socio-economic; children; education; employment

\begin{abstract}
The fundamental importance of the family as being the heart of the world's socio-economic, moral and political affairs has been the focus of society. The study examined the extent to which, family size, income and the employment status of parents could predict parents' investment in children's education. The findings generally point to a weak positive and statistically significant relationship between investment in children's education and the family size, and parents' income. The study also found that the burden of the direct cost of education is more on the public than on the parents as only two percent of parents' additional income is invested in children education, which points to the unemployment situation of parents in Nigeria as one of the possible influences. The paper calls for the inclusion of other variables such as sociological, environmental, demographic and urbanization in a further study.
\end{abstract}

\section{BACKGROUND TO THE STUDY}

The Nigerian governments like most governments in the developing countries face enormous challenges in their efforts to deliver social services-water, electricity, basic education, roads, communication networks and other infrastructures. More often than not, the provisions of these basic social services are in rudimentary stages and are strained to capacity. Hence, the family and parents' role in the decision to send their children to school and thus invest in their education is very candid and fundamentally paramount in such a society where free and compulsory universal basic education is not enforced by government or socially unaffordable. Indeed, in matters of educational investment and family planning, or population control, policies targeted at meeting the individual family needs appear more fulfilling and result oriented than those that address national needs. This view was succinctly expressed by Adjaero (1996) that the family is the heart of the world's problems and at the Rubicon of it's salvation for if it were possible to heal the family, it would be possible to heal the world. The social and economic bonds in a family tend to be great, particularly in the developing countries where the economic value of the child to the family is high. In fact, because of government inability to help families to prevent or ban child labour and enforce compulsory basic education, the economic viability of the child to the Nigerian family has been enormous, parti- cularly to the poorer families. Indeed, the fundamental importance of the family as an agent for human growth and development and for the welfare of the entire society cannot be overemphasized. The family is very influential in creating and reflecting the strengths and weaknesses of the larger society. As Adjaero (1996) commented, education and socialization of children are the primary ways through which a society creates its future. The family is more than just a collection of people with biological, social, moral and economic ties. To Ross et al. (1990), Zimmer et al. (2001) it is in the family that the larger social and economic order impinges on individuals, exposing them to varying degrees of hardship, frustration and struggle. The family therefore, has very strong interacting influences on members in diverse ways. Education, the world over, has come to be accepted as the most consistent and reliable measure of socioeconomic status determination of individuals in societies. It helps to place persons into statuses. The beauty of education is that it has very limited errors of reporting and accounting, compared to other socio-economic status determinants like wealth or income. Education is measured as a categorical variable that reflects no formal or low formal education, middle and high levels of education attainment (Winkleby et al., 1992). The basic responsibilities of the traditional family which remained housing, clothing, health care, nutrition and safety, have in modern times included the provision of quality education and 
a homely condition with necessary facilities that support child learning. As a measure of socioeconomic status determinant, families regard education as a means of maintaining their status or improving it. This perhaps, explains why high socio-economic status families tend to show much concern over their children's poor performance at school either by teaching them those subjects in which the children perform poorly or employing part-time teachers for them. Today, most high socio- economic status families strive to maintain their status by ensuring that their children attend the best nursery and primary schools which guarantee admission to highly placed secondary schools, provide the best routes to university education and thus guarantee access to a prestigious occupation and employment and enhanced income. Over the years, there has been much controversy on the impact of family size on educational investment in children. While some authorities Ahlburg and Kelley (1996); Anh et al. (1998); Allison (2003) testify to a weak relationship; others, Todaro (1977); Lloyd (1994), Nyenke (2004) and Eriemo (2004) feel that other demographic and educational factors are highly influential. These studies actually link family size to child labour and school enrolment. No doubt, decisions regarding family size and educational investment in children are made independently at distinct times. However, because of economic realities of the time, such decisions are taken proactively, in cognizance of the educational implications. For, in reality, family investment in children's education is financed primarily through reduced consumption. Yet, other consumption demands of the family in the form of feeding, clothing, shelter, entertainment and others keep rising with time, just as the cost of educating the child skyrockets. From economic point of view, the household demand for education is inversely related to its private costs. The higher the cost of educating the child, the lower would be the household demand for education, holding income and other variables constant. Like the neo-classical theory of household choice for goods, services, leisure and education, a family's decision to have additional children certainly has sociological and economic rationality. In the views of Todaro (1977), Eriemo (2004), it is assumed that the household demand for the first two or three children is relatively fixed and determined largely by the cultural or psychological consumption factors while the demand for additional children are weighed purely on cost-benefit analysis. In the developing countries, however, having many children is desirable for both economic and psychological reasons. More often than not, children tend to provide a readily pool for farm labour and they constitute a regular source of finance to their parents from very tender ages and continue to fed for them till old age. This tends to minimize the parents' cost of rearing the child and increasing the benefits derivable. The more the children therefore, the more the benefits, particularly at old age. This was the thinking of the yesteryears, popular among the poor and illiterate farmers. In modern times, however, modernization, urbanization, and education have changed this psychology. In addition, as parents become more of urban, fixed wage earners who no longer consider child labour as economical or worthwhile, child rearing has become increasingly costly. The educated and well-informed parents, who also have higher income tend to appreciate more the value and benefits of education and higher standard of living for themselves and children and therefore; more likely to desire fewer children so as to be able to effectively give them higher level of education and higher standard of living. With globalization, access to better-paid jobs is dependent on the quality of education, qualifications possessed; while access to quality education, and enhanced qualifications are closely tied to socio- economic status of family. The higher the socio-economic status of the family, the better schooling for the children and hence the better qualifications and better-paid jobs. This, the Berker's (1960) quantity-quality trade-off model and the Resource Dilution Theory succinctly portrays. The Berker model posits that an increase in the demand for child quality reduces the demand for quantity, both through the shadow income constraint and by raising the shadow price of quantity. An increase in the demand for quantity reduces the demand for quality by a similar mechanism. The preceding analysis strongly supports the micro-economic theory of fertility. The theory posits that: (1) parents may produce more children than they actually desire in the expectation that some will not survive; (2) that there is a strong intrinsic satisfaction from family formation, so that children, especially the first two or three, can also be viewed as alternative "consumer goods in their parents' decision making process. Beyond this, 
the economic choice mechanism sets in for every additional child born. The economic benefits derivable there from are viewed in terms of the expected income from child labour and their later financial support at parents' old age. Against these benefits are the principal elements of costs: the opportunity cost of the mothers' income forgone as she stays at home caring for the children and the actual cost of educating the children. Therefore, a cost-benefit analysis is often carried out, weighing the economic benefits against costs. Like the traditional theory of consumer behaviour, the micro-economic theory of family fertility leads to the conclusion that as the price or cost of child rearing increases, parents demand for additional number of children diminishes. It is nevertheless true that children impose certain costs as well as benefits on their parents. The economic costs of large family could be the difficulty in providing education for the children to improve their quality; difficulty in feeding, clothing and sheltering the family. In which case, fertility should be higher when income is sufficiently high to bear the explicit and perhaps implicit costs. However, although increased income may enable the family to support more children, the evidence seems to show that with higher incomes, parents will tend to substitute child quality for quantity by investing in fewer, more educated children whose eventual earnings capacity will be much higher (Todaro, 1977). In general, the more rapid the population growth rate, the greater will be the proportion of dependent children in the total population and the more difficult it becomes for those who are working to support those who are not. In other words, such a population tends to be youthful with grave consequences such as increased education burden on the family and society. No wonder, Todaro hypothesized that higher birth rates are generally associated with national poverty, and indeed, higher levels of living provide the necessary motivations for families to choose to limit their size. All things being equal, as the family experiences fixed and limited time and financial resources, and with fixed allocation of these resources, additional children imposes additional burdens on the family. Within individual households, it is implied that family size corresponds to a decreased investment of parental time and money in the education of each child. Even as the resources available to the family are limited in supply, the needs of every additional child must be met; an indication that the limited resources will be spread thinner as the family increases. This perspective which is known as "the dilution effect" recognizes that education; especially beyond the primary level is expensive and that the resources needed to provide this education are limited. This was further expressed by Psacharopoulos and Woodhall (1997), when they posited that not only are the direct and indirect costs of education significant determinants of demand for children, but the way in which these costs are shared between parents, the extended family (including siblings), and government influences parents' perceptions of the economic burden or advantage of an additional child.

Various studies Psacharopoulos and Woodhall (1997), Tinker et al. (2000), Ashford (2001), Akpotu (2005) have shown that women in many developing countries, particularly those from the poorest households, with no schooling or with lower education have the highest fertility. This no, doubt suggests a vicious circle of poverty and illiteracy as the situation is worst among the poor. This finding appears universal in all regions of the world, including wealthier regions (Ashford, 2001). The implication of the findings on the capability of such nations and households to invest on education is grave. The poor, in most cases, are always the first to drop out of school, have less chance of completing any level of education cycle because; the implicit and explicit private costs of education to the poor family is often higher. Yet, the benefits of primary education are still lower for poor students (Todaro, 1977; Coombs, 1985; Psacharopoulos and Woodhall, 1997; UNESCO, 1998). Thus, making the family's rate of returns on investment in a child's education to be lower for the relatively poor than for the relatively rich. Education is certainly a strong determinant of earnings; hence, investment in education geared towards equalization of educational opportunities could help to equalize incomes in the future. Indeed, since the development of the human capital theory in the 1960's, development economists as well as educational economists and planners have continued to argue that investment in education does not only contribute to economic growth and development, but also act as a long- term strategy for equalizing earnings and income distribution. To Todaro (1977), there is a positive correlation between a person's education and his lifetime 
earnings and this is especially true for those who are able to complete secondary and university education where an income differential is very substantial. In addition, access to jobs is predicated almost exclusively on educational credentials irrespective of the relationship between years of schooling and job performance; and family's income serves as the basic criterion of who is able to proceed up the educational ladder to highly paid jobs. In the past, parents' natural desire to have large family size created no serious socioeconomic problems. Breeding children then cost almost nothing. With the battered Nigerian economy and the souring cost of living, breeding children has become very expensive, and with the increasing cost of education, sponsoring many children in secondary and post secondary schooling can be quite formidable on parents, even on their substantial income. This certainly supports the assertion of Ahlburg and Kelley (1996), Ebenuwa-Okoh et al. (2004) that large numbers of social deviants such as juvenile delinquents and prostitutes come from families, which are at least too large for proper parental control and training. In the same vain, Akpotu and Jike (2004) have lent support to the claim that there is a positive correlation between level of educational attainment and involvement in crimes. As Nigeria and most other African countries continue to witness high illiteracy rates, with many school age children out of school with increasing number of school dropouts, children from larger and poorer families would appear to be more disadvantaged. More so, the role of extended families and governments in sharing the burden of post-secondary education has be encountering difficulties. This forms the premise for this study, which attempts to examine family size, parents' socio-economic variables as predictor of investment in children education in south-west Nigeria.

\section{METHODOLOGY}

Sample and Sampling Procedures: The South-West Nigeria formally referred to as the Western Region constitutes the present states of Delta, Edo, Ekiti, Lagos, Ogun, Ondo, Osun and Oyo. The region, which forms the population of the study, is specifically known for a long outstanding tradition of warm embrace to western education. Apart from being the first to have mission school established in Badagery, near Lagos, in 1843, Fafunwa (1974); Adesina (1982);
Yesufu et al. (1996); it was also the first to be associated with track records of huge investments in the provision of universal free primary education (Taiwo, 1980, and Adesina, 1982).

The married couples, which represent families in the region with children in secondary and post-secondary educational institutions, formed the target subjects. A total of three thousand one hundred and fifty- three couples/ families were sampled for the study. Of that number, two thousand, two hundred and three representing 69.9 percent of the total sample was used for the analysis. The sample size was drawn from six local government areas in each of the eight states that made up the study population. The six local government areas in each state were chosen on the average of two from each of the three senatorial districts. From each of the 48 local government areas, 66 families with children in secondary and tertiary institutions and with varied educational backgrounds and employment statuses were drawn.

The data generated were analyzed, using the ordinary least squares (OLS) estimating technique. This technique is preferred to the correlation analysis because of the large sample size (Kerlinger, 1992). The OLS results are presented in Table 1.

\section{RESULTS}

As shown in Table 1, the constant value (C) is statistically significant at 1 percent. This implies that there are other omitted significant factors that could influence parents' decisions to investment in their children education other than these factors studied.

The number of children per parents (NOCPP) is found to be positively related to investment in children education as a priori expected. This variable is also statistically significant at 3 percent. This positive relationship indicates that an increase in the number of children in schools induces higher investment spending in education

The Income per parents (IPP) coefficient was also found to be positive and statistically significant at 1 percent as expected a priori. This indicates that as family income increases, family investment on children' education also increases.

The Employment status of parents (ESOF) is not statistically significant although it is positively related to investment in children education. However, the F- statistic (3.73) a global 
Table 1: Un-weighted least squares linear regression of investment in children education. Dependent Variable: INVC

\begin{tabular}{|c|c|c|c|c|}
\hline Independent Variables: & Coefficient & Standard Error & $t$-Statistic & Probability \\
\hline$\overline{\mathrm{C}}$ & 102067.7 & 11287.5 & 9.04258 & 0 \\
\hline NOCPP & 2999.073 & 1399.62 & 2.14278 & 0.0322 \\
\hline ESOF & 4.06762 & 858.832 & 0.00474 & 0.9962 \\
\hline IPP & 0.014539 & 0.00564 & 2.57813 & 0.01 \\
\hline R-squared & 0.005069 & Mean dependent & Variable & 125074 \\
\hline Adjusted R-squared & 0.003712 & S.D. dependent & Variable & 340871 \\
\hline S.E.of regression & 340237.9 & Akaike info & Criterion & 28.3145 \\
\hline Sum Squared residual & $2.55 \mathrm{E}+14$ & Schwarz & criterion & 28.3248 \\
\hline Log likelihood & -31184.41 & F-statistic & & 3.73454 \\
\hline Durbin-Watson stat. & 1.594783 & Prob. (F-statistic) & & 0.0108 \\
\hline
\end{tabular}

INVC: Investment in Children Education

$C$ : Constant

NOCPP: Number of children per parents

ESOF: Employment status of Family

$I P P:$ Income per parents

test; which reports the overall significance of the explanatory variables is statistically significant at 1 percent level of test. So also is the DurbinWatson statistic of 1.6 suggests absence of serial or auto-correlation.

\section{DISCUSSION}

The study examined the extent to which family size, family income and the employment status of parents could predict parents' investment in their children's education. The findings generally point to a weak positive and statistically significant relationship between the dependent and independent variables. In fact, the low coefficients of determination as reported by the R-squared and Adjusted R-squared indicate that other significant factors that explain variation in investment in children education have not been captured by this study. This supports the works of Todaro (1977), Lloyd (1994), Nyenke (2004), and Eriemo (2004) to the effect that demographic and educational factors are influential. Perhaps, parental, sociological, environmental or urbanization and psychological determinants may also be important regressors of parents investment in children' education.

Although literature is mixed on the a priori relationship being studied, the findings support the works of Ahlburg and Kelley (1996); Anh et al. (1998), Allison (2003) who testified to a weak relationship. But one way to explain this weak, but positive and significant relationship between number of children per parents and investment in children education is the fact that as family size increases, there is the probability of such families resorting to dis-savings and re- allocation of family resources at the expense of other basic needs. Also, the extended family system which encourages cooperation and collective responsibility in educating members of the extended family could help to cushion the educational burden on the direct parents. The Nigerian situation is such that the burden of education is borne mainly by the government through free tuition at all levels of the educational system in public schools. Thus, indications are that only the indirect cost and minimal direct cost of education burden are borne by parents. This is sufficiently supported in the data analysis which further shows that education in Nigeria remains largely a public or social good. For example, the IPP t-test statistic value suggests that two kobo of every one naira increase in parents' income is spent on children's education. The fact that only 2 percent of parents' additional income is invested in children's education no doubt suggests a very low private marginal propensity to invest in children's education. This has far reaching implications on "the dilution effect" in the face of increasing contending demands for the scarce government resources. It further highlights the unemployment situation of parents, which among others is responsible for the low level of parents investment in children education.

It will be recalled that factors such as sociological, environmental, demographic and urbanization are some other determinants of investment expenditure of parents in children education, their non-inclusion in the analysis of this study constitute one limitation which may serve as basis for further study. 


\section{REFERENCES}

Adesina, S. 1982. Planning and Educational Development in Nigeria. $2^{\text {nd }}$ Ed.. Ibadan: Educational Industries Nigeria Limited.

Adjaero, N. M. 1996. The Structure of the Family: A Social Institution Onitsha, Nigeria: Spiritan Publications.

Ahlburg, D.A. and A. C. Kelley. (Eds.) 1996.. "The consequences of rapid population growth on human resource development: The case of education" from The Impact of Population Growth on Well-Being in Developing Countries

Akpotu, N.E. and V. T. Jike. 2004. "An Analysis of the Link between Education and Crime: Prison Inmates' Perception in Nigeria" The African Symposium. An On-Line Journal of the African Educational Research Network (AERN) Vol. 4. No. 4, December. WEBSITE: http: //www2.ncsu.edu/ncsu/aern/dec04.html

Akpotu, N.E. 2005. "Education as Correlate of Fertility Rate Among Families in Southern Nigeria" The African Symposium. An On-Line Journal of the African Educational Research Network (AERN) Vol.5, No. 2, July. Pp.5- 15.

Allison, V. 2003. Does Large Family Size Reduce Investment in Children?-NotMuch"cheetah. middle bury.edu/_hortache/popdev_k/Topics/CONFERENCES/ Food/vrat

Anh, T.S., J. Knodel, D. Lam, and J. Friedman. 1998. "Family size and children's education in Vietnam." Demography, 35: 57-70.

Ashford, I. S. 2001. "New Population policies:Advancing women's health and rights." Population Bulletin (PRB) Washington, DC, 56(1): 3-12.

Coombs, P.H. 1985. The World Crisis in Education: The View from the Eighties. New York: Oxford University Press.

Ebenuwa-Okoh, E. E., R. N. Osakwe and F. J. Oluwole. 2004. "Child Labour, its Consequences on the overall Development of the Girl Child", (Pp. 63-71) in V. T. Jike (ed.), The Scourge of Child Labour in Nigeria: A Book of Readings. Lagos: Nigerian Sociological Society.

Eriemo, N. A. 2004. "Elitism and the Family- Size Question: The Demand for Children Across University Workers", (Pp. 205-222) in V. T. Jike (ed.), The Scourge of Child Labour in Nigeria: A
Book of Readings. Lagos: Nigerian Sociological Society.

Fafunwa, A. B 1974. History of Education in Nigeria. London: George Allen and Unwin.

Kerlinger, F. N.1992. Foundations of Behavioral Research. $3^{\text {rd }}$ Ed : New York: Harcourt Brace College Publishers.

Lloyd, C.B. 1994. "Investigating in the next Generation: The Implications of high fertility at the level of the family." New York Population Council, Research Division Working paper ENo.63.

Nyenke, C 2004. "Socio-Psychological Analysis of Child Labour in Port Harcourt" (Pp. 131-147) i in V. T. Jike (ed.), The Scourge of Child Labour in Nigeria: A Book of Readings. Lagos: Nigerian Sociological Society.

Psacharopoulos, G. and M. Woodhall. 1997. Education for Development: An Analysis of Investment Choices. New York: Oxford University Press.

Ross, C.E.J., J. Mirowsky and K. Goldsteen. 1990. "The Impact of the Family on Health: The Decade in Review." The Journal of Marriage and Family. 52: 1059-1078 www.prc.utexas.edu/profiles/docs/ Ross_C_bio.pdf

Taiwo, C.O.1980. The Nigerian Educational System: Past, Present and Future. Lagos: Nelson (Nigeria) Limited.

Tinker, A., K. Finn and J. E. Epp. 2000. Improving Women's Health. Issues and Interventions. Washington DC: The World Bank, June 2000, 10,

Todaro, M.P. 1977. Economics for a Developing World. London: Longman

UNESCO 1998. Annual Report January-December 31 1997. Paris: UNESCO..

Wickleby, M.A., D. E. Jatulis, E. Frank, and S. P. Fortmann. 1992. "Socio-economic Status and Health: How Education, Income, and Occupation Contribute to Risk Factors for Cardiovascular Diseases." American Journal of Public Health, 82 (6): $816-820$

Yesufu, J. T., I. F. Izekor and A.I.O. Ikekhua. 1996. History of Western and Nigerian Education. BeninCity: Uri Publishing Ltd.

Zimmer, Z., A. I. Hermalin and H. S. Lin. 2001. "Whose Education Counts? The Impact of Grown Children's Education on the physical Functioning of their Parents in Taiwan." Asia-Pacific Regional Conference for the International Year of Older Persons. Hong Kong, No.146. 